\title{
Fernando de Andréa
}

A atividade física e o enfrentamento do estresse em idosos.

Dissertação apresentada à Faculdade

de Medicina da Universidade de São Paulo para obtenção do Título de Mestre em Ciências.

Área de concentração: Educação e Saúde Orientador: Prof. Dr. Wilson Jacob Filho

São Paulo - 2010 
Dados Internacionais de Catalogação na Publicação (CIP)

Preparada pela Biblioteca da

Faculdade de Medicina da Universidade de São Paulo

Creprodução autorizada pelo autor

Andréa, Fernando de

A atividade física e o enfrentamento do estresse em idosos / Fernando de Andréa. -- São Paulo, 2010.

Dissertação (mestrado)--Faculdade de Medicina da Universidade de São Paulo. Departamento de Clínica Médica.

Área de concentração: Educação e Saúde.

Orientador: Wilson Jacob Filho.

Descritores: 1.Idoso 2.Atividade física 3.Adaptação psicológica 4.Estresse psicológico

USP/FM/SBD-021/10 


\section{Dedicatórias}

À minha mãe e irmãos, que tanto me incentivaram e apoiaram.

Às minhas tias que me ajudaram.

À minha namorada Lívia por sua paciência.

Ao meu orientador e conselheiro Wilson Jacob Filho, que proporcionou esta oportunidade. 
"Se eu vi mais longe, foi por estar de pé sobre ombros de gigantes"

Isaac Newton

\section{Agradecimentos}

À todos que colaboraram e tornaram este trabalho possível de ser realizado.

À minha mãe, Isabel, por seu apoio.

Ao meu irmão Paulo pela sua iniciativa e sugestões em meu trabalho.

Ao meu irmão Eduardo pelo seu apoio.

À minha namorada Lívia por sua paciência.

Às minhas tias Mara Mercedes e Mara Helena por seu suporte científico e sugestões.

Ao meu orientador Wilson Jacob Filho por sua dedicação ao nosso projeto.

À Fernanda Varkala Lanuez que participou muito desta pesquisa, em vários aspectos.

À Adrina Nunes responsável pela estatística deste trabalho.

Às secretárias do Serviço de Geriatria do HC-FMUSP, Juliana e Rosany. 


\section{SUMÁRIO}

\section{INTRODUÇÃO}

1.1- O processo de envelhecimento 1

1.2- O Envelhecimento Fisiológico 2

1.3- Qualidade de vida e envelhecimento 4

1.4- Capacidade Funcional na Velhice 5

1.5- Atividade física habitual 8

$\begin{array}{ll}\text { 1.6- Estresse } & 10\end{array}$

1.7- Fontes de estresse e estressores 11

1.7.1- Fontes externas 11

1.7.2- Fontes internas 12

$\begin{array}{lll}\text { 1.8- Coping } & 13\end{array}$

1.8.1- Modelos de Coping 14

1.8.2- Coping em idosos 15

1.9- A relação entre atividade física e estresse em idosos 18

2. OBJETIVOS DO ESTUDO 20

3. CASUÍSTICA E MÉTODOS 21

4. RESULTADOS 24

5. DISCUSSÃO 30

6. CONCLUSÕES 32

7. REFERÊNCIAS

8. ANEXOS 40 


\section{LISTA DE GRÁFICOS}

Gráfico $01 \quad$ Perfil da Atividade Humana

Gráfico 02 Inventário de Estratégias de Coping

Gráfico 03 Perfil da Atividade Humana e Inventário de Estratégias de Coping 


\section{LISTA DE ANEXOS}

Anexo 1 Documento de aprovação CAPPesq

Anexo 2 Termo de Consentimento Livre e Esclarecido (TCLE)

Anexo 3 Inventário de estratégias de coping de Folkman e Lazarus

Anexo 4 Inventário do Perfil da Atividade Humana (PAH)

\section{LISTA DE TABELAS}

Tabela 1 Coeficiente de Correlação de Pearson entre as variáveis 


\section{LISTA DE ABREVIATURAS}

AAAOC Associação Atlética Acadêmica Osvaldo Cruz

AIVD Atividades Instrumentais na Vida Diária

AVD Capacidade Funcional as Atividades da Vida Diária

FMUSP Faculdade de Medicina da Universidade de São Paulo

HC Hospital das Clínicas

IBGE Instituto Brasileiro de Geografia e Estatística

PAH Perfil de Atividade Humana

WHOQOL World Health Organization Quality of Life (Questionário sobre Qualidade de Vida da Organização Mundial de Saúde) 


\section{RESUMO}

Introdução: Embora muitos estudos tenham demonstrado diferentes efeitos da prática de Atividade Física por idosos, o relato de melhora das condições psíquicas e emocionais e da capacidade funcional para as atividades cotidianas ainda carece de maiores comprovações. Objetivo: analisar o valor de um programa de atividade física no enfrentamento do estresse em idosos. Métodos: Estudo de intervenção em um grupo de 18 idosos encaminhados do ambulatório do Serviço de Geriatria do HC-FMUSP, aderentes a um programa de atividade física supervisionado e avaliados pelo Perfil da Atividade Humana (PAH) e pelo Questionário de Coping. Resultados: nas escalas de avaliação de coping e de desempenho funcional, foi verificado um incremento da capacidade de enfrentamento do estresse e melhora nas atividades cotidianas após a prática do programa de atividade física . Conclusões: A pratica de atividade física regular e orientada, mesclando trabalho aeróbio, de resistência, de alongamento e respiratórios produz efeitos positivos na capacidade de coping e na de realização das suas atividades cotidianas.

Descritores: idoso, atividade física, enfrentamento, estresse. 


\begin{abstract}
Introduction: there are many studies which have demonstrate different effects of the physical activities program on the elderly people fitness, but the effects on the psychological and emotional profile and the daily live activities have been done. Objective: To analyze the value of a physical activity program on the elderly stress coping. Methods: Intervention study in a group of 18 elderly coming from the Geriatric Service of the Medical College Hospital, University of São Paulo (HCFMUSP), which were adherent to a physical activity program that were supervised and evaluated by the Human Activity Profile (PAH) and the Coping Questionnaire. Results: An increment in the stress coping capacity and an improving of the daily activities were verified after the physical activity program practicing. Conclusions: The practice of supervised and regular physical activity intercalating aerobic with resistance, stretching, and respiratory exercises yield positive effects in the coping capacity and in the accomplishment of the daily activities.
\end{abstract}

Keywords: elderly, physical activity, coping, stress. 


\section{INTRODUÇÃO}

O Brasil, segundo dados do Instituto Brasileiro de Geografia e Estatística (IBGE), possuía uma população de 7,7 milhões de indivíduos com mais de 60 anos de idade em 1980, sendo que este número dobrou nos últimos vinte anos. As projeções indicam que em 2025 o Brasil deverá possuir uma população de 34 milhões de idosos, o que corresponderá a aproximadamente $14 \%$ de sua população. Constatase, assim, que o processo de envelhecimento populacional, antes restrito aos países desenvolvidos, também está ocorrendo na população brasileira e de forma ainda mais acelerada (IBGE, 2000).

\section{1 - O processo de envelhecimento}

Jacob-Filho (2003) ressalta a importância de saber distinguir entre os efeitos naturais do processo de envelhecimento, denominado senescência (também encontrado na literatura como: eugeria ou envelhecimento primário), das alterações produzidas pelas diversas doenças que podem acometer o idoso, configurando o que se chama de senilidade (patogeria ou envelhecimento secundário). Tal distinção é necessária para compreendermos que o envelhecimento não é uma doença, mas sim um processo fisiológico, embora determinadas enfermidades sejam mais freqüentes nesta fase da vida.

O processo de envelhecimento deve ser visto em sua totalidade, uma vez que envolve diversos fatores e pressupõe alterações físicas, sociais e psicológicas. 
Neste sentido, Beauvoir (1970) afirma que a velhice " é um fenômeno biológico: o organismo do homem idoso apresenta certas singularidades. A velhice acarreta, ainda, conseqüências psicológicas: certos comportamentos são considerados, com razão, como característicos da idade avançada. Como todas as situações humanas, ela tem uma dimensão existencial: modifica a relação do homem com o tempo e, portanto, sua relação com o mundo e com sua própria história. Por outro lado, o homem não vive nunca em estado natural; na sua velhice, como em qualquer idade, seu estatuto lhe é imposto pela sociedade à qual pertence".

\section{2- O Envelhecimento Fisiológico}

O processo de envelhecimento é um processo biológico natural do ciclo de vida e, como tal, se caracteriza por diversas alterações. Dentre elas, modificações físicas que envolvem mudanças na anatomia e fisiologia. Passarelli (1997) apresenta algumas delas:

-Alterações cerebrais: redução da massa a do volume do encéfalo, perda neuronal e aumento do volume de liquido encéfalo raquidiano..

-Alterações cardiovasculares: aumento da rigidez do coração, diminuição da complacência ventricular e da frequiência cardíaca máxima.

-Alterações respiratórias: aumento do diâmetro da caixa torácica, diminuição da elasticidade pulmonar e aumento do volume residual..

-Alterações osteoarticulares: perda progressiva da massa óssea, alterações hormonais que caracterizam, por exemplo a menopausa.

-Alterações dos sistemas sensoriais: perda da acuidade dos órgãos sensoriais, como a visão, audição, o tato e o sistema vestibular. 
Kenney (1989) apresenta um modelo de categorização das alterações decorrentes do envelhecimento, considerando quatro tipos de modificações funcionais:

- Perda total da função, como por exemplo, a habilidade para escutar sons acima de certa freqüência ou a capacidade reprodutiva da mulher;

- Perda parcial da função na qual há uma perda de unidades anatômicas sendo mantida a capacidade funcional, como por exemplo, perdas de fibras musculares.

- Nível reduzido de eficiência, sem que haja perda da unidade funcional, como a do controle de temperatura ou da excreção renal de ácidos.

- Alterações secundárias hormonais como os níveis de testosterona masculinos.

Com isto, o sistema biológico fica mais fragilizado, deixando o idoso mais suscetível a doenças como: quadros demenciais, diabetes, hipertensão e demais doenças crônicas em geral.

Segundo Kenney (1989), as mudanças fundamentais do envelhecimento também ocorrem em níveis celulares e subcelulares. Desta forma, não apenas as capacidades funcionais sofrem alterações, mas a anatomia geral é alterada, como: redução da altura e de peso, alteração na pele (como perda de elasticidade e aumento da fragilidade), redução do perímetro cefálico, dentre outros.

Contudo, não devemos entender tais modificações como sendo obrigatoriamente restritivas, pois estas levam, em geral, a um declínio de função em harmonia com uma exigência menor de consumo metabólico.

Em decorrência, há uma diminuição da reserva funcional de cada órgão e sistema, que não deve ser confundida com insuficiência. 


\section{3-Qualidade de vida e envelhecimento}

Através de seu contato com a população idosa no âmbito hospitalar, Aranha (2003) pôde constatar que "muito da problemática vivenciada no processo de envelhecimento se encontra relacionada à qualidade de vida e aos vínculos por ele desenvolvido durante a vida".

A representação de Qualidade de Vida relacionada ao processo de envelhecimento envolve diversos fatores. Se pensarmos primeiramente em representação, concordaremos com Aranha (2003) quando esta afirma que "estudar e tentar entender as possíveis representações é algo um tanto complexo, que envolve não só o conhecimento dos meios sociais nos quais os indivíduos encontram-se inseridos, mas também a estrutura psíquica que os sustentam e os resultados deste processo."

Embora não haja definição consensual de qualidade de vida, THE WHOQOL GROUP (1995) aponta para o fato de que há uma considerável concordância entre os pesquisadores acerca de algumas características que envolvem tal constructo. Citam três características: subjetividade, multidimensionalidade e bipolaridade como as mais importantes desta composição. Quanto à primeira característica subjetividade - observa-se que está interrelacionada às condições externas, como trabalho, família e os demais laços sociais que permeiam a vida do idoso e que influenciam a sua qualidade de vida. A segunda característica multidimensionalidade - detém um maior consenso entre os pesquisadores, uma vez que dimensões tais como físicas, psicológicas e sociais estão sempre incluídas nas diversas definições de qualidade de vida. Tais dimensões convergem sempre na direção da subjetividade, ou seja, como os indivíduos percebem seu estado físico, ou as suas relações interpessoais. Quanto à bipolaridade, é possível perceber que tal constructo possui dimensões positivas (como autonomia) e negativas (como dor ou 
dependência). Contudo, sempre devem ser enfatizadas as percepções individuais de cada dimensão.

Neste sentido, concordamos com Paschoal (2004) que define qualidade de vida como sendo "a percepção do indivíduo acerca de sua posição na vida, de acordo com o contexto cultural e os sistemas de valores nos quais vive e em relação a seus objetivos, expectativas, padrões e preocupações."

\section{4-Capacidade Funcional na Velhice}

Consideram-se os principais componentes da capacidade funcional as atividades da vida diária (AVD), que incluem a alimentação, a higiene pessoal, a locomoção em casa ou ambiente plano, o vestuário e a comunicação enquanto que as atividades instrumentais na vida diária (AIVD) incluem o uso correto dos medicamentos, a manipulação do dinheiro, a orientação fora de casa, o uso do telefone ou de um equipamento eletrodoméstico, segundo Andreotti e Okuma (1999).

De acordo com Schoueri Júnior, Ramos \& Papaléo Netto (1994), tradicionalmente o envelhecimento foi um fenômeno sempre estudado e analisado como uma característica de países europeus, pois nessas regiões $28 \%$ da população apresenta idade superior a 65 anos.

A partir da década de 50, no entanto, tem ocorrido um crescimento expressivo da população idosa nos países de terceiro mundo. Spirduso (1989) comenta que o século XX foi palco de drásticas mudanças de demografia relacionadas à idade. Dados apresentados pela autora mostram que, em 1900, somente 4\% da população mundial apresentavam idade igual ou superior a 65 anos. No ano 2000, projeta-se que 15 a $20 \%$ da população pertencerão a essa categoria. Ressalta-se ainda que a 
população dos muito idosos (indivíduos acima dos 80 anos), desde 1940, tem crescido mais de 50\% a cada década Pescatello \& Di Pietro (1993); Spirduso, (1989). Na América Latina, estima-se que entre os anos de 1980 e 2000, a população idosa aumentará em $236 \%$ e o Brasil, em 2025, terá a sexta maior população idosa no mundo Schoueri Júnior et alii (1994).

Segundo Kalache, Veras \& Ramos (1987), no Brasil, entre os anos de 1950 e 2025, o aumento da população idosa será da ordem de 15 vezes, enquanto o da população como um todo será de não mais que cinco vezes no mesmo período.

Sem dúvida, o aumento da expectativa de vida proporciona às pessoas um maior período de tempo para sintetizar e culminar a realização de seus projetos de vida. Porém, para que isso ocorra, é necessário que a velhice seja vivida com qualidade Okuma et alli (1995).

Infelizmente, o aumento do número de idosos na população tem se traduzido em um maior número de problemas de longa duração, seja em nível pessoal ou social Kalache et alli (1987)

Em nível pessoal, Pescatello \& Di Pietro (1993) citam que aproximadamente 80\% das pessoas acima de 65 anos apresentam ao menos um problema crônico de saúde. Da mesma forma, Okuma (1997) ressalta que grande porcentagem de pessoas acima de 60 anos tem algum tipo de dificuldade para realizar atividades cotidianas. Em nível social, Schoueri Júnior et alii (1994) citam que na Inglaterra, 17\% de pessoas com mais de 65 anos utilizam 60\% do orçamento do Departamento Nacional de Saúde e Cuidados Sociais. Em 1980, o gasto "per capita" que esse departamento teve com indivíduos com mais de 75 anos foi cerca de oito vezes maior que com a população geral.

Tem sido preocupação dos vários domínios da ciência descobrir as virtudes da velhice, prolongar a funcionalidade e envelhecer com boa qualidade de vida individual e social. Em decorrência do evidente aumento da população idosa mundial, identificar as condições que permitem envelhecer bem se torna tarefa de 
várias disciplinas no âmbito das ciências biológicas, psicológicas e sociais Lawton (1991); Neri (2001).

Não é suficiente considerar apenas o aumento da expectativa de vida da população. É necessário avaliar se os anos adicionais à vida de um indivíduo serão saudáveis o suficiente para lhe conferir autonomia e independência.

Segundo Hayflick (1996), o desejo de avaliar as condições nas qual o indivíduo vive seus últimos anos de vida criou uma variante denominada "expectativa de vida ativa, saudável ou funcional. A expectativa de vida ativa termina quando a saúde de uma pessoa se deteriora a ponto de provocar a perda de sua independência nas atividades da vida cotidiana, tornando-se dependente de outros ou de algum tipo de assistência".

Um dos elementos que determinam a expectativa de vida ativa ou saudável é a independência para realização de AVD. Sem dúvida, na velhice, a capacidade de realizar estas atividades pode sofrer alterações, segundo Adrian (1986); Aniansson, Rundgren \& Sperling, (1980); Gallahue (1995); Mendes De Leon, Seeman, Baker, Richardson \& Tinetti, (1996); Seeman, Bruce \& McAvay (1996).

Nota-se uma forte tendência à diminuição da atuação do indivíduo no meio em que vive. Tanto nas ações motoras mais específicas, como nas mais genéricas, pode-se observar um especial comprometimento na participação da maior parte da população idosa.

Considerando o envelhecimento como um processo multidimensional e singular, Spirduso (1995) identifica cinco categorias hierárquicas que detectam os diferentes níveis de capacidade funcional em idosos:

- fisicamente dependentes: pessoas que não podem executar atividades básicas da vida diária (como vestir-se, tomar banho, comer) e que dependem de outros para suprir as necessidades diárias; 
- fisicamente frágeis: indivíduos que conseguem executar atividades básicas da vida diária, mas não todas as atividades instrumentais da vida diária;

- fisicamente independentes: podem realizar todas as atividades básicas e instrumentais da vida diária, mas são geralmente sedentários;

- fisicamente ativos: realizam exercícios regularmente e aparentam ser mais jovens que sua idade cronológica;

- atletas: correspondem à pequena porcentagem da população, pessoas engajadas em atividades competitivas.

\section{5.- Atividade física habitual}

A atividade física regular é considera-da um componente importante para um estilo de vida saudável. Recentemente, essa constatação foi reforçada por novas evidências científicas de que a atividade física regular pode trazer benefícios para a saúde física e mental. No entanto, milhões de adultos ainda se encontram sedentários, segundo Pate (1995).

Além de a atividade física ser um fator importante na qualidade de vida das pessoas, há evidências de que a população que mais se beneficia dela são os idosos, conforme Nieman (1999). A atividade física habitual envolve o tempo gasto com as atividades motoras desenvolvidas no trabalho, para se deslocar de um lugar ao outro, no lazer, no esporte, nos exercícios físicos e nas atividades domésticas e de jardinagem Nahas (2001).

Pesquisas que comparam grupos de adultos e idosos, bem como pesquisas longitudinais que acompanharam o desenvolvimento e o envelhecimento de um grupo de indivíduos, indicam que exercícios físicos realizados regularmente 
favorecem a capacidade física, a resistência e a flexibilidade, aumentam a velocidade psicomotora e o desempenho neuropsicológico. Há evidências também de que a participação em atividades físicas e sociais pode prevenir, evitar e diminuir o estresse e aumentar a resistência a doenças Vitta (2000).

A recomendação e orientação sobre o nível de prática da atividade física para adultos e idosos são apresentadas como uma das formas de prevenção secundária das doenças crônicas, a exemplo dos importantes benefícios demonstrados em pacientes com doenças cardiovasculares Yusuf et alli (1996).

Os cuidados com a saúde e a prática de atividades físicas atuam como mecanismos preventivos. Pesquisas sugerem que aproximadamente $50 \%$ do declínio freqüentemente atribuído ao envelhecimento fisiológico, na realidade, é provocado pela atrofia do desuso, como conseqüência da inatividade, levando à diminuição da resistência física, à fraqueza generalizada e às quedas.

A prática de atividades físicas assegura a maior independência, autonomia e melhor condição de saúde, aumentando o senso de bem-estar, a crença de autoeficácia e a capacidade do indivíduo de atuar sobre o meio ambiente ou sobre si mesmo, segundo Vitta (2000).

\section{6- Estresse}

O termo stress, cunhado originalmente em inglês (em português, estresse), deriva do latim stringere e significa apertar, cerrar, comprimir Houaiss et al. (2001), embora o 
seu conceito tenha sido primeiramente descrito por Hans Seyle, em 1956, que o definiu como sendo, essencialmente, o grau de desgaste total causado pela vida.

Estresse pode ser definido como um estado de tensão que causa uma ruptura no equilíbrio interno do organismo, ou seja, um estado de tensão patogênico do organismo. $\mathrm{O}$ desequilíbrio ocorre quando a pessoa necessita responder a alguma demanda que ultrapassa sua capacidade adaptativa Everly (1990).

A fonte de tensão pode ser externa ao próprio organismo, como uma exigência de algo ou alguém, ou interna, exemplificada como uma autodemanda, ou autocobrança Lazarus (1966).

Os primeiros estudos sobre stress na área da saúde foram realizados na década de 1930, por Hans Selye, que definiu a reação do stress como "uma síndrome geral de adaptação na qual o organismo visa readquirir a homeostase perdida diante de certos estímulos".

Como nos define Lipp e Malagris (1995), Selye (1974) redefiniu o termo stress como "resposta não específica do corpo a qualquer exigência".

O stress pode ser definido como: "uma reação do organismo, com componentes físicos e/ou psicológicos, causada pelas alterações psicofisiológicas que ocorrem quando a pessoa se confronta com uma situação que, de um modo ou de outro, a irrite, amedronte, excite ou confunda, ou mesmo que a faça imensamente feliz" Lipp \& Malagris ( 2001).

Os estudos de Selye (1965) o levaram a concluir que o processo do stress é constituído de três fases: alerta, resistência e exaustão. A primeira fase - alerta acontece no momento em que a pessoa se depara com a fonte estressora e, nesse enfrentamento, se desequilibra internamente, apresentando sensações características, tais como sudorese excessiva, taquicardia, respiração ofegante e picos de hipertensão. A segunda fase - resistência - caracteriza-se por uma tentativa de recuperação do organismo após o desequilíbrio sofrido na fase anterior. Nesse 
momento ocorre um gasto de energia que pode ocasionar cansaço excessivo, problemas de memória e dúvidas quanto a si próprio Caso o equilíbrio não seja readquirido por meio dessa mobilização, o processo pode evoluir para a terceira fase - exaustão -, quando ressurgem sintomas ocorridos na fase inicial, no entanto, com maior agravamento Lipp \& Malagris (2001).

Importante ressaltar que na fase de exaustão ocorre um grande comprometimento físico que pode se manifestar em forma de doenças Lipp \& Novaes (1996).

\section{7-Fontes de estresse e estressores}

As fontes de estresse podem ser classificadas em externas e internas. Fontes externas englobam eventos que não dependem diretamente do controle do indivíduo, isto é, mudanças inesperadas, problemas do cotidiano, acidentes ou doenças, por exemplo. Já as fontes internas estão diretamente relacionadas à pessoa e aos comportamentos privados, podendo constituir- -se do padrão comportamental apresentado, nível de assertividade, vulnerabilidade, entre outros Lipp (1996).

\subsection{1-Fontes externas}

Toda mudança significativa gera uma necessidade de adaptação por parte do organismo e essa, por sua vez, exerce um papel determinante na patogênese do estresse Holmes e Rahe (1967). À medida que o ser humano passa por mudanças, ele utiliza suas reservas de energia adaptativa e, conseqüentemente, pode, em certas circunstâncias, enfraquecer sua resistência física e mental, dando origem a inúmeras doenças psicofisiológicas que podem ser interpretadas como tendo em sua gênese o estresse emocional excessivo Toates (1999). 
As mudanças ocorridas na sociedade moderna são marcantes. Elas são excitantes, frenéticas e, muitas vezes, rápidas demais para permitirem ao homem uma absorção do seu ritmo e do seu significado. A competição excessiva, o desejo intenso de "possuir", a pressa, o medo do outro ser humano, a pressão diária que as pessoas bem sucedidas impõem, inegavelmente afetam seu desempenho cotidiano. Desse modo, a qualidade de vida é prejudicada, pois uma constante de insegurança e incerteza necessariamente fica aquém do que se almeja como uma vida de boa qualidade Lipp e Rocha (1996).

\subsection{2-Fontes internas}

Além das causas externas de estresse mencionadas acima, que são fáceis de serem reconhecidas, existem outras causas que nem sempre são discutidas Lipp (2000). Referem-se aqui a expectativas irrealistas, cognições distorcidas, perfeccionismo, sonhos inalcansáveis, desejos e fantasias que passam a ser vistos como realidades que cada ser humano muitas vezes tem para si próprio e para os outros ao seu redor. Alguns estados emocionais também podem assumir a função de geradores de estados tensionais, como, por exemplo, um transtorno de ansiedade, o qual pode ser uma fonte poderosa de estresse porque o ser humano ansioso possui a tendência a ver o mundo de modo ameaçador, como se houvesse sempre um risco das coisas não darem certo. Assim, aquilo que para as outras pessoas representaria somente um desafio, para quem tem ansiedade parece uma batalha muito grande. Aqueles que percebem os desafios como gigantescos, logicamente se estressam mais (Lipp, 2000).

As fontes externas e internas de estresse se somam na determinação de nível de estresse que será experimentado, porém a somatória dos estressores é mediada por 
dois fatores importantes, que são o repertório de estratégias de coping e sua vulnerabilidade ao estresse (Lipp, 2000).

\section{8 - Coping}

Coping é concebido como o conjunto das estratégias utiliza das pelas pessoas para adaptarem-se a circunstâncias adversas. Os esforços despendidos pelos indivíduos para lidar com situações estressantes, crônicas ou agudas, têm se constituído em objeto de estudo da psicologia social, clínica e da personalidade, encontrando-se fortemente atrelado ao estudo das diferenças individuais.

As maneiras como as pessoas lidam com situações estressantes e circunstâncias adversas em seu dia-a-dia despertam interesses de pesquisadores há algum tempo.

$\mathrm{O}$ estudo deste processo tem sido realizado sob o construto denominado coping Lazarus e Folkman (1984); Vaillant (1994) ou respostas de enfrentamento Seidl, Tróccoli e Zannon (2001). Refere-se, especificamente, ao conjunto de esforços cognitivos e comportamentais realizados pelo indivíduo com o objetivo de lidar com as demandas (internas e/ou externas) que sobrecarregam ou excedem seus recursos pessoais Lazarus e Folkman (1984).

Historicamente, três gerações de pesquisadores têm-se dedicado ao estudo do coping. Diferenças marcantes podem ser observadas em suas construções, tanto no nível teórico quanto no nível metodológico, decorrentes de suas filiações epistemológicas Suls, David \& Harvey (1996).

Desde o início do século, pesquisadores vinculados à psicologia do ego têm concebido o coping, enquanto correlato aos mecanismos de defesa, motivado interna e inconscientemente como forma de lidar com conflitos sexuais e agressivos Vaillant (1994). Eventos externos e ambientais, posteriormente incluídos como 
possíveis desencadeadores dos processos de coping foram, a exemplo dos mecanismos de defesa, categorizados hierarquicamente no sentido dos mais imaturos aos mais sofisticados e adaptativos Tapp (1985). Assim, para esta primeira geração de pesquisadores, o estilo de coping utilizado pelos indivíduos era concebido como estável, numa hierarquia de saúde versus psicopatologia.

\subsection{1-Modelos de Coping}

Numa perspectiva cognitivista, Folkman e Lazarus (1980) propõem um modelo que divide o coping em duas categorias funcionais: coping focalizado no problema e coping focalizado na emoção. Esta construção baseou-se em análises fatoriais que geraram dois fatores principais utilizados pelos pesquisadores para definir os dois tipos de estratégias de coping. Nesta perspectiva, coping é definido como um conjunto de esforços, cognitivos e comportamentais, utilizado pelos indivíduos com o objetivo de lidar com demandas específicas, internas ou externas, que surgem em situações de stress e são avaliadas como sobrecarregando ou excedendo seus recursos pessoais Lazarus \& Folkman (1984). Esta definição implica que as estratégias de coping são ações deliberadas que podem ser aprendidas, usadas e descartadas.

Portanto, mecanismos de defesa inconscientes e não intencionais, como negação, deslocamento e regressão, não podem ser considerados como estratégias de coping. Além disso, somatização, dominação e competência são vistos como resultados dos esforços de coping e não como estratégias Ryan-Wenger (1992).

O modelo de Folkman e Lazarus (1980) envolve quatro conceitos principais:

- coping é um processo ou uma interação que se dá entre o indivíduo e o ambiente; 
- sua função é de administração da situação estressora, ao invés de controle ou domínio da mesma;

- os processos de coping pressupõem a noção de avaliação, ou seja, como o fenômeno é percebido, interpretado e cognitivamente representado na mente do indivíduo;

- o processo de coping constitui-se em uma mobilização de esforço, através da qual os indivíduos irão empreender esforços cognitivos e comportamentais para administrar (reduzir, minimizar ou tolerar) as demandas internas ou externas que surgem da sua interação com o ambiente.

Segundo Beresford (1994), este modelo tem sido referido como o mais compreensivo dentre os até então existentes

\subsection{2-Coping em idosos}

De acordo com dados do IBGE (2004), a população de idosos vem aumentando nos últimos anos. Estudos apontam uma queda da natalidade e um número crescente de idosos.

No ano de 2000, 30\% da população estava situada na faixa etária de zero a 14 anos, enquanto os maiores de 65 anos representavam apenas 5\% dos brasileiros. A estimativa é de que, em 2050, estes dois grupos se igualem, representando, cada um, $18 \%$ da população.

Este aumento da expectativa de vida para os idosos é conseqüência de vários fatores. Fatores esses que contribuem também para a melhoria na qualidade de vida. A medicina cada vez mais avançada, melhorias ambientais e materiais, sistemas educacionais e meios de comunicação mais efetivos, melhores recursos psicológicos, tais como leitura e escrita em computadores, aumento da prática da 
atividade física e muitos outros fatores, estão fazendo com que os idosos se aproximem do seu limite de máxima duração de vida em condições mais saudáveis (Baltes \& Smith, 2006).

Freire (2000), assim como nós, acredita que esta etapa da vida pode ser de realizações e felicidade, uma vez que os idosos podem certamente estar integrados ao convívio social e satisfeitos com eles próprios. Eles têm potencialidades que, através de aprendizagem, exercícios ou treinamentos, possibilitam novos conhecimentos, tanto teóricos quanto práticos. Além disso, segundo a psicogerontologia, o idoso tem grande capacidade de compensar as perdas decorrentes do processo de envelhecimento baseando-se nas experiências de sucesso e fracasso ocorridos ao longo de sua vida e nas expectativas que possui em relação ao futuro e a ele próprio.

Além do mais, conforme afirmam Freire e Resende (2001), se envelhecimento bem sucedido significasse boa saúde física e ausência de limitações, não haveria como dar sentido à existência de deficientes físicos - de ordem inata ou adquirida, ou das pessoas que estão doentes. Por isso, não se pode dizer que declínio físico seja sinônimo de falta de sentido e qualidade de vida, pois muitos envelhecem com qualidade e continuam ativos, com objetivos e metas a atingir.

Freire (2000) defende também que a:

- auto-aceitação;

- relações positivas com os outros;

- autonomia;

- domínio sobre o ambiente;

- presença de propósitos de vida; e,

- direcionamento voltado para o crescimento pessoal

Podem transformar a velhice em um período de satisfação e bem estar psicológico. 
Porém, não devemos nos esquecer de que a velhice também é uma etapa que promove alterações contextuais que podem representar desafios pessoais ao idoso. O corpo começa a mostrar alterações naturais, decorrentes de seu envelhecimento, como, por exemplo, a diminuição de memória recente e da massa muscular, queda do nível de gordura sob a pele, diminuição da elasticidade do coração, artéria e pulmões, aparecimento de rugas, entre outros Olds \& Papalia (2000). Também é comum a perda de entes queridos e saída dos filhos de casa, além da diminuição de renda, principalmente em virtude da aposentadoria.

Caso o idoso não lide bem com as adversidades que a velhice lhe impõe, todos estes fatores podem se transformar em fontes estressoras Goldstein (1995).

Os eventos estressores podem ser classificados em Zakir (2001).:

- microestressores;

- situações contínuas de vida

- eventos vitais.

O primeiro tipo inclui todos os acontecimentos do cotidiano que produzem reações que passam despercebidas, mas que tem um efeito acumulativo importante, destacando-se, por exemplo, os conflitos interpessoais.

Quanto às situações contínuas de vida, pode-se dizer que apresentam maior cronicidade e se relacionam à identidade do indivíduo. A forma de convívio que a pessoa estabelece com seus vizinhos pode ser considerada um tipo de situação contínua de vida.

Os eventos vitais, por sua vez, são aqueles que causam mudanças significativas no ambiente pessoal e normalmente estão associados à etiologia de doenças.

Alguns idosos encontram dificuldades em se adaptar às mudanças que vêm com a velhice, e isto reflete em sua qualidade de vida. A falta de recursos, tanto internos quanto externos (saúde debilitada, habilidades sociais diminuídas, pouco suporte 
social, entre outros), aumenta a susceptibilidade do idoso aos eventos estressores e influencia na forma de enfrentamento dessas situações. Neste sentido, os seis aspectos que Freire (2000) propõe, aliados a uma história de vida favorável, proporcionam adaptações à velhice e, conseqüentemente, um envelhecimento satisfatório.

\section{9-A relação entre atividade física e estresse em idosos}

Do ponto de vista de Okuma (1998), o bem-estar físico é relevante para lidar com quase todos os eventos estressantes e o indivíduo idoso que se sente com mais recursos físicos (como saúde, energia e melhor capacidade funcional), sente-se mais competente e seguro conseguindo ter assim, serenidade para lidar com os acontecimentos, estressantes ou não, que ocorrem a sua volta.

Dá-se aí a importância do idoso praticar atividade física com o propósito de prevenir ou apenas tentar atenuar seu estresse. Utilizando a atividade como estratégia de coping ou enfrentamento do estresse.

Okuma (1998) apresenta como conclusão da revisão de literatura realizada por McAuley \& Rudolph (1995) que 74\% dos estudos revisados evidenciaram a ocorrência de efeitos positivos da atividade física sobre o bem estar psicológico, tais como, sentir-se mais competente, mais satisfeito com a vida, em melhor estado de ânimo e conseqüente redução nos níveis dos afetos negativos.

De acordo com Roizen (1999), praticar exercícios é uma das melhores formas de reduzir o estresse. O exercício metaboliza os hormônios do estresse no sangue, aumentando os níveis dos hormônios antiansiedade do organismo e provocam uma sensação de calma.

Com relação ao Domínio Saúde Mental, McAuley \& Rudolph (1995) observam que a maioria dos estudos, nesta área, tende a focar os efeitos da atividade física na redução do estresse ou ansiedade e depressão, o que, de acordo com essa visão, a 
concepção de saúde mental ou bem estar psicológico se reduz sobremaneira. McAuley \& Rudolph (1995), que descrevem a saúde mental ou psicológica sob dois aspectos com componentes positivos que dizem respeito aos aspectos cognitivos, autoestima e autoeficácia e componentes negativos que englobam a depressão, a ansiedade e estresse.

Pesquisas que comparam grupos de adultos e idosos de diferentes idades, bem como pesquisas longitudinais que acompanharam o desenvolvimento e o envelhecimento de um grupo de indivíduos, indicam que exercícios físicos realizados regularmente favorecem a capacidade física, a resistência e a flexibilidade, aumentam a velocidade psicomotora e o desempenho neuropsicológico. Há evidências também de que a participação em atividades físicas e sociais pode prevenir evitar e diminuir o estresse e aumentar a resistência a doenças Vitta (2000).

Existem evidências de que a atividade física favoreça o bem estar psicológico. As pesquisas indicam que a prática de atividade física modifica a capacidade de lidar com o estresse através do aumento dos recursos físicos e psicológicos atingidos com o exercício Spirduso (2005).

Harris et al. (2006) examinaram a associação entre a atividade física, praticada regularmente com o objetivo de redução do estresse, depressão e variáveis demográficas em bases de 1, 4 e 10 anos. Maior nível de atividade física foi associado com menos depressão, mesmo quando foi considerado gênero, idade, problemas médicos e eventos de vida (estressores). A atividade física reduziu os efeitos das condições médicas e dos eventos de vida negativos na depressão, mas apenas quando ela foi realizada com o objetivo de redução de estresse.

Estes resultados permitem sugerir que a atividade física pode auxiliar no enfrentamento dos agentes estressores, mas para isto ela deve estar vinculada ao objetivo de redução do estresse Luft (2007). 


\section{OBJETIVOS}

\section{Geral:}

Verificar o impacto de um programa de atividade física em idosos, avaliando a sua capacidade de enfrentamento do estresse e o seu nível de atividades cotidianas.

\section{Específicos:}

- Distinguir os efeitos no primeiro e no segundo período de 6 meses de treinamento.

- Avaliar se a prática prévia de atividade física determina diferenças no impacto do programa atual.

- Avaliar se há diferença do impacto quanto à idade dos praticantes. 


\section{CASUÍStiCA E MÉTOdo}

Trata-se de um estudo de intervenção, sem grupo controle, com início em março de 2007 e término em março de 2008, aprovado pelo Comitê de Ética em Pesquisa do Hospital das Clínicas da Faculdade de Medicina de São Paulo (CAPPesq-HC Anexo 1).

Os idosos foram encaminhados pelo ambulatório do Serviço de Geriatria do HCFMUSP, fossem eles praticantes prévios de atividade física no passado ou fossem indivíduos sedentários. Originalmente foram selecionados 22 indivíduos, porém apenas 18 participaram de todas as etapas da pesquisa.

Todos os participantes assinaram o Termo de Consentimento Livre e Esclarecido (TCLE - Anexo2).

As atividades foram realizadas na Associação Atlética Acadêmica Osvaldo Cruz (AAAOC), no ginásio coberto e na pista de atletismo (400m), três vezes na semana (segunda, quarta e sexta), com duração de 50 minutos cada sessão, por doze meses.

As atividades foram elaboradas, dirigidas e ministradas pelo próprio pesquisador.

Cada sessão constituída de:

- Alongamento e aquecimento com exercícios específicos executados durante cerca de 10 minutos.

- Prática de exercícios utilizando materiais específicos para realização de resistência muscular localizada tal como; extensores de borracha, bolas de borracha, cordas e bastões. Esta prática com duração por 15 minutos.

- Caminhada monitorada pela pista de 400 metros, por 20 minutos.

-Exercícios de respiração e relaxamento por cinco minutos. 
Foram utilizados dois inventários para a coleta de dados, aplicados no início (T0), aos 6 meses (T1) e ao final de 12 meses (T2), aplicados pelo próprio pesquisador:

- Inventário de estratégias de coping de Folkman e Lazarus - corresponde a um questionário de 66 itens, onde estão destacados pensamentos e/ou ações utilizadas para lidar com demandas externas e internas em face de um evento estressante específico (12). Este inventário é composto por oito fatores (confronto, afastamento, autocontrole, suporte social, aceitação de responsabilidade, fuga e esquiva, resolução de problemas e reavaliação positiva), que denotam o tipo de enfrentamento utilizado pelo indivíduo frente ao estresse. É composto por pensamentos e ações, podendo ser definida a intensidade do uso por meio de escala de 0 (não utiliza) a 3 (utiliza em grande quantidade). Os itens que compõem o inventário foram divididos em oito fatores: confronto, afastamento, autocontrole, busca de suporte social, aceitação de responsabilidade, fuga e esquiva, planejamento e resolução de problemas, reavaliação positiva. Tal instrumento foi traduzido, adaptado e validado no Brasil (Savóia, 1996- Anexo3).

- Inventário do Perfil da Atividade Humana (PAH) - questionário com 94 itens de atividades graduadas de acordo com o equivalente metabólico, que tem sido utilizado em idosos e pacientes neurológicos crônicos. As atividades incluem cuidados pessoais, tarefas domésticas, transporte, atividades sociais, de lazer e exercícios físicos. O questionário fornece três alternativas de respostas (ainda faço, parei de fazer e nunca fiz) e o resultado apresenta o Escore de Atividade Ajustado (EAA), subtraindo-se do Escore Máximo de Atividade (EMA) o número de itens que o indivíduo parou de fazer. Na tentativa de superar os problemas associados à utilização de escalas fáceis, Daughton et al. desenvolveram a primeira versão do Perfil de Atividade Humana (PAH), denominado Human Activity Profile, originalmente destinado a avaliar indivíduos com doença pulmonar obstrutiva crônica. Em 1988, Fix \& Daughton propuseram algumas 
modificações estruturais no instrumento, que passou a ser utilizado na avaliação do nível funcional e de atividade física, tanto para indivíduos saudáveis, em qualquer faixa etária, quanto para aqueles com algum grau de disfunção . Para evitar dificuldades no preenchimento e garantir a presença de vários níveis de dificuldade, os autores procuraram selecionar atividades rotineiras, que variassem de um nível funcional baixo (levantar e sentar em cadeira ou cama sem ajuda) a um nível funcional alto (correr 4,8 quilômetros em menos de 30 minutos) Fix \& Daughton (1988) . Os 94 itens do instrumento, quando categorizados de acordo com a classificação internacional de funcionalidade (Organização Mundial de Saúde, 2003), abordam os domínios atividade e participação. Esta escala foi traduzida, adaptada e validada no Brasil por Savóia (1996- Anexo 4) .

A análise estatística foi realizada utilizando o programa MINITAB 14. Após uma análise descritiva dos resultados, foram aplicados os testes de Correlação de Pearson bem como o teste $\mathrm{T}$ para as variáveis com distribuição normal. Foi considerado significativo o valor de $\mathrm{p}<0,05$. 


\section{4-RESULTADOS}

Os 18 indivíduos analisados variaram em idade de 60 a 89 anos, com média de 74,5 anos todos do sexo feminino.

Podemos visualizar melhor os resultados obtidos na tabela 1:

Tabela 1.

Coeficiente de Correlaçào de Pearson entre: idade, Perfil de Atividade Humana e Inventário de Estratégia de Coping nos três tempos de avaliação $(\mathrm{T} 0=$ início, $\mathrm{Tl}=6$ meses, $\mathrm{T} 2=12$ meses $)$.

\begin{tabular}{|c|c|c|c|c|c|c|}
\hline & pahTo & pahr1 & pahT2 & coping T0 & copingT1 & coping T2 \\
\hline pahT1 & $\begin{array}{l}0,996 \\
0,000\end{array}$ & & & & & \\
\hline pahT2 & $\begin{array}{l}0,928 \\
0,000\end{array}$ & $\begin{array}{l}0,942 \\
0,000\end{array}$ & & & & \\
\hline copingTO & $\begin{array}{l}0,718 \\
0,001\end{array}$ & $\begin{array}{l}0,721 \\
0,001\end{array}$ & $\begin{array}{l}0,715 \\
0,001\end{array}$ & & & \\
\hline copingT1 & $\begin{array}{l}0,665 \\
0,003\end{array}$ & $\begin{array}{l}0,670 \\
0,002\end{array}$ & $\begin{array}{l}0,668 \\
0,002\end{array}$ & $\begin{array}{l}0,984 \\
0,000\end{array}$ & & \\
\hline copingT2 & $\begin{array}{l}0,564 \\
0,015\end{array}$ & $\begin{array}{l}0,579 \\
0,012\end{array}$ & $\begin{array}{l}0,714 \\
0,001\end{array}$ & $\begin{array}{l}0,838 \\
0,000\end{array}$ & $\begin{array}{l}0,829 \\
0,000\end{array}$ & \\
\hline idades & $\begin{array}{l}-0,519 \\
0,027\end{array}$ & $\begin{array}{l}-0,509 \\
0,031\end{array}$ & $\begin{array}{l}-0,568 \\
0,014\end{array}$ & $\begin{array}{l}-0,397 \\
0,103\end{array}$ & $\begin{array}{l}0,448 \\
0,062\end{array}$ & $\begin{array}{l}-0,408 \\
0,092\end{array}$ \\
\hline
\end{tabular}


Foi verificado um aumento significativo nos valores do perfil de PAH nos tempos seis meses (T1) e 12 meses (T2) em relação a avaliação inicial (T0), ou seja, durante todo o período de estudo.

No coping houve um aumento significativo nos primeiros seis meses de atividade, que se manteve estável até o final do estudo.

A distribuição destes resultados pode ser melhor visualizada nos gráficos 1e 2: 
Gráfico1: Perfil da Atividade Humana nas três avaliações: inicial (T); aos 6 meses (T1) e aos 12 meses (T2)). T0xT1 - p=0,000; T1xT2 - p=0,018 e T0xT2 - $p=0,001$

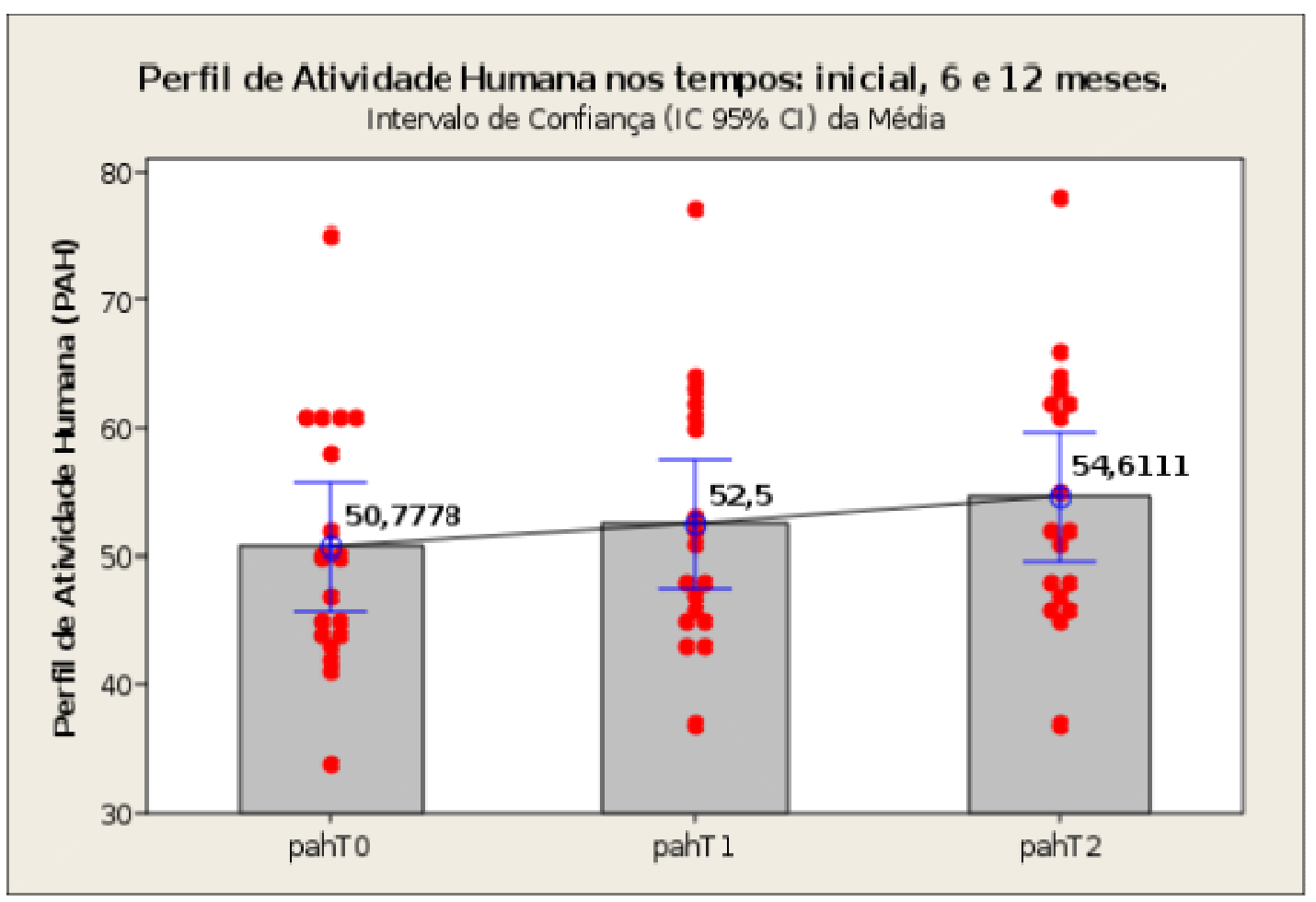


Gráfico 2 : Inventário de estratégias de coping nas três avaliações: inicial (T0); aos 6 meses (T1) e aos 12 meses (T2). (T0xT1 - p=0,000; T1xT2 - p=0,143 e T0xT2 $\mathrm{p}=0,010$ )

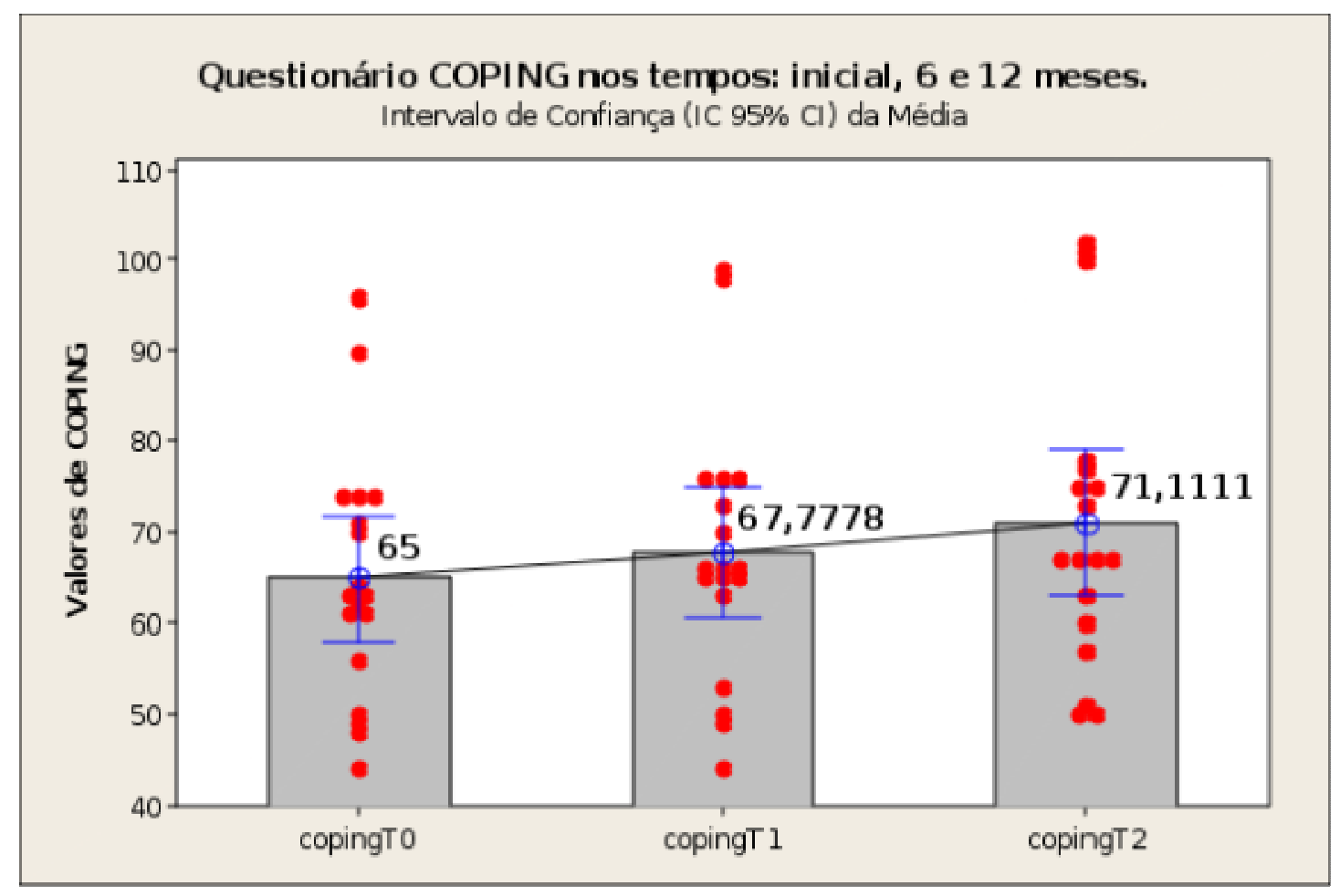


Houve correlação diretamente proporcional entre o aumento de PAH e coping em T0, T1 e T2 p<=0,05. Gráfico 3:

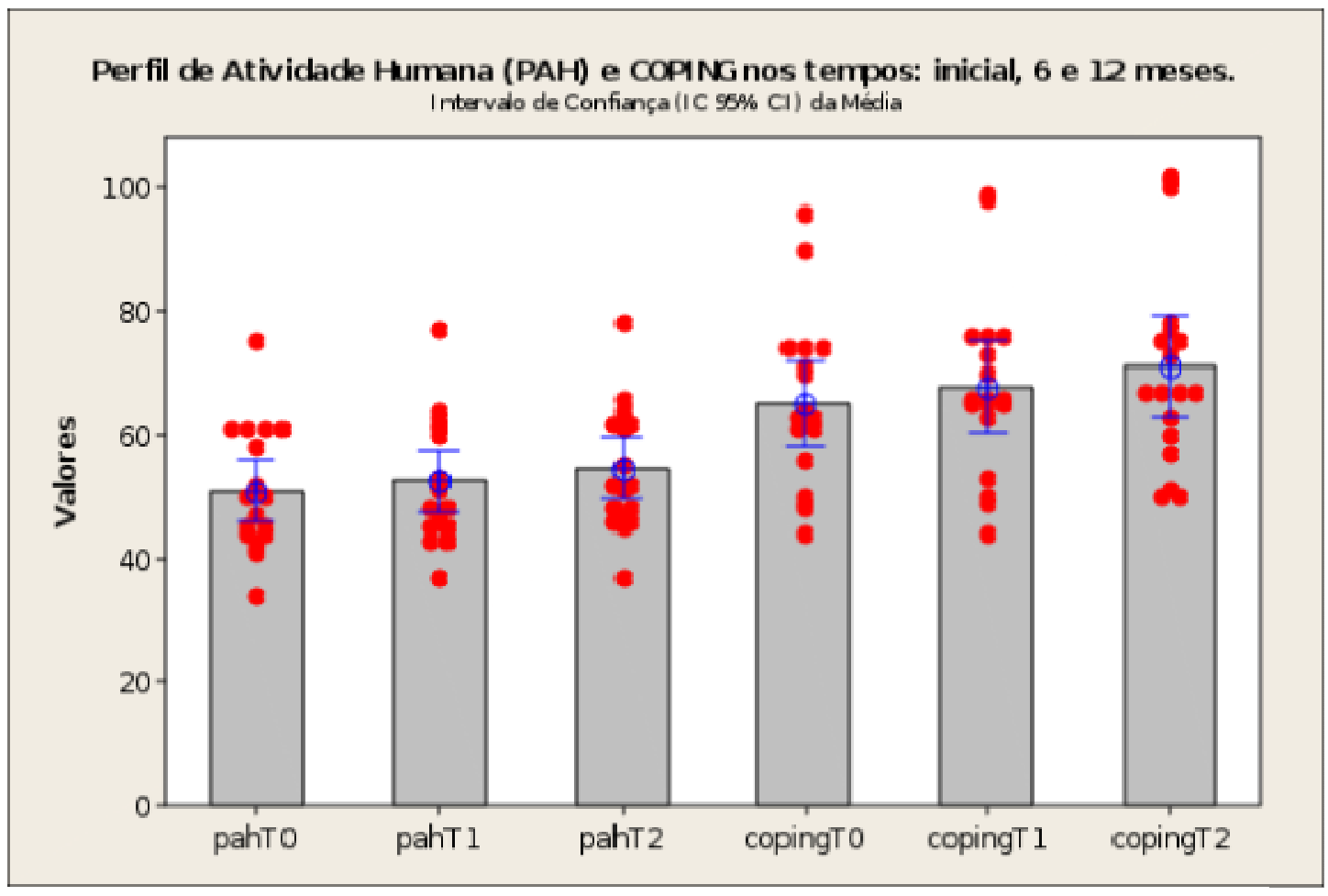


Dividindo em subgrupos dos que praticavam atividades físicas antes do início do estudo e os que não praticavam, ou seja, sedentários, obtivemos os seguintes resultados.

Indivíduos que já praticavam atividade física prévia $(10=55,6 \%)$ :

No PAH tivemos aumento significativo, $p=0,000$ entre o início e seis meses e depois uma estabilização nos últimos seis meses.

No coping obtivemos aumento significativo, $\mathrm{p}=0,007$ nos primeiros seis meses das atividades e depois também uma estabilização.

Indivíduos que não praticavam atividade prévia $(8=44,4 \%)$ :

No PAH tivemos aumento significativo nos primeiros seis meses de estudo, $\mathrm{p}=0,000$ e também nos últimos seis meses do estudo, $\mathrm{p}=0,009$.

No coping obtivemos aumento significativo apenas nos primeiros seis meses, $\mathrm{p}=0,032$ e depois uma estabilização nos últimos seis meses.

Os indivíduos mias idosos apresentaram uma capacidade física (PAH) proporcionalmente menor durante todo o estudo, no entanto, é interessante notar que as estratégias de coping não mostraram alteração com o avançar da idade.

Dividindo os idosos em dois grupos etários, o primeiro com menos de 75 anos $(10=$ $55,6 \%)$ e o segundo com 75 anos ou mais $(8=44,4 \%)$, evidenciamos, neste, um aumento progressivo do PAH aos 6 e aos 12 meses de estudo, enquanto que entre os menos idosos, a elevação inicial até os 6 meses segue-se de uma estabilização até o final. 


\section{5-DISCUSSÃO}

O presente estudo avaliou a influencia da atividade física sobre alguns aspectos da relação entre o indivíduo idoso e o seu enfrentamento do estresse (coping).

Para tal, preferimos não apenas determinar a evolução da capacidade de enfrentamento do estresse, avaliada pelo Inventário de Estratégias de Coping mas também associar uma avaliação do reflexo desta capacitação nas atividades cotidianas, avaliadas.

Em relação ao Inventário de estratégias de coping,obtivemos que este demonstrou um aumento significativo nos primeiros seis meses de atividade, tendendo, posteriormente, a uma estabilização no segundo período, levando-nos a crer que a atividade física, tendo em vista o enfrentamento do estresse, mostra seus efeitos mais evidentes na fase inicial do processo, permanecendo eficaz na sequência da intervenção.

Em relação ao Perfil de Atividade Humana (PAH), verificamos que este demonstrou um aumento no desempenho funcional nos dois momentos de avaliação (6 e 12 meses), indicando que a melhora das atividades cotidianas do grupo ao longo do programa se mantém progressiva durante o período de intervenção. .

Neste estudo foi verificada relação significativa entre prática regular de atividade física e o enfrentamento do estresse como relatado em estudos anteriores Atlantis et al. (2005) Harris et al.(2006); Kause et al.( 1993).

Temos que salientar, porém, que o estudo de Krause et al. (1993), não apenas demonstrou nítida relação entre atividade física e estresse, mas também que os idosos expostos a determinados agentes estressores tendem a diminuir a frequiência de prática de atividade física. Estas pesquisas sugerem que quanto 
melhor as condições de saúde dos idosos, maiores as chances de se engajarem em programas de atividade física.

Daí decorre uma das nossas principais preocupações com a maior possibilidade de evasão dos programas de atividade física destinados a idosos. Sabemos que é freqüente a ocorrência de fatores estressores nesta faixa etária e, consequentemente, caso atinjam o indivíduo ainda desprotegido das suas principais estratégias de enfrentamento, as conseqüências poderão afastá-lo de uma das melhores possibilidades de adquiri-las, que é o programa de atividade física no qual está inserido.

Um dos nossos objetivos foi, também, realizar uma comparação entre duas faixas etárias, visto que nossa população incluiu idosos com grande variação de idades (60 a 89 anos), mas não conseguimos identificar diferença significativa entre os grupos em nenhuma das variáveis estudadas. Isto nos permite afirmar que, pelo menos nesta casuística, os efeitos advindos de um programa de atividade física supervisionado não são prejudicados pelo avançar da idade, ocorrendo na mesma magnitude entre os assim chamados "idosos jovens" e os "muito idosos".

Da mesma forma, também tentamos demonstrar a existência de comportamento diferenciado entre o grupo previamente praticante de atividades físicas e aqueles considerados sedentários e o principal aspecto que merece ser salientado é que o grupo previamente praticante teve seus efeitos evidentes, em ambas variáveis, no primeiro semestre, mantendo-os inalterados no segundo, enquanto que os sedentários mostraram continuidade da sua evolução funcional também na segunda fase da pesquisa.

Um aspecto bastante positivo é que a atividade física proposta é de baixo custo, passível de ser realizada em locais públicos, desde que supervisionados por profissionais competentes (professores de educação física ou fisioterapeutas com formação gerontológica), com o respaldo de uma equipe multidisciplinar e geriatria, levando a crer que esta prática deva ser difundida para o bem estar geral dos idosos sem a dependência de equipamentos de alta complexidade ou de ambientes muito 
sofisticados, o que inviabiliza a extensão destes programas para a maioria da população.

Reconhecemos que uma das principais limitações deste estudo foi o pequeno número de praticantes, devido à maior dificuldade em manter a freqüência $\mathrm{e}$ adesão à prática de atividade física regular durante o período de 12 meses, condição fundamental para a inclusão neste estudo, visto que estes indivíduos apresentam várias intercorrências que podem dificultar sua locomoção ao local de prática das atividades físicas ou mesmo a sua execução por períodos contínuos.

Outro fator limitante que merece ser ressaltado é a ausência de grupo controle, que pode ser explicado pela forte recusa dos idosos selecionados em permanecerem sem atividade durante um período tão prolongado.

\section{6-CONCLUSÕES}

A prática de atividade física regular e orientada incrementa o grau de enfrentamento do estresse no indivíduo idoso, e também amplia o seu desempenho físico nas atividades cotidianas.

Não há diferença entre os benefícios obtidos, tanto no enfrentamento do estresse como nas atividades cotidianas, nas diferentes faixas etárias $(60-74$ anos e 75 ou mais anos) dentre os idosos. 
O grupo previamente sedentário tem efeitos de implementação das atividades cotidianas progressivos durante todo o período de estudo. 


\section{7- REFERÊNCIAS}

1. Adrian, M.J. Research for independent living among the elderly. In: McPherson, B.D., ed. Sport and aging. Champaing, Human Kinetics, 1986. p.137- 43.

2. Andreotti, R. A.; Okuma, S. S. Validação de uma bateria de testes de atividades da vida diária para idosos fisicamente independentes. Revista Paulista de Educação Física, São Paulo, v. 13, n. 1, p. 46-66, jan./jun. 1999.

3. Aniansson, A.; Rundgren, A.; Sperling, L. Evaluation of functional capacity in activities of daily living in 70-year-old men and women. Scandinavian Journal of Rehability Medicine, v.12, p.145-54, 1980.

4. Aranha, V. C. A representação social do envelhecimento e os determinantes afetivoemocionais: semelhanças e conflitos entre idosos e não idosos usuários do HCFMUSP. Dissertação Mestrado em Psicologia, Faculdade de Saúde Pública a Universidade de São Paulo, p.2-63, São Paulo, 2003.

5. Atlantis, E; Chow Chin-Moi; Kirby, A; Fiatarone, S. An effective exercise-based intervention for improving mental health and quality of life measures: a randomized controlled trial. Preventive medicine, v. 39, n.2, p.424-434, 2005.

6. Baltes, Paul B; SMITH, Jacqui. Novas fronteiras para o futuro do envelhecimento: da velhice bem sucedida do idoso jovem aos dilemas da quarta idade. A Terceira Idade, São Paulo, v.17, n.36, p.7-31, jun. 2006.

7. Beauvoir, S. (1970). A velhice. São Paulo: Difusão Européia do Livro.

8. Daughton DM, Fix AJ, Kass I, Bell CN, Patil KD. Maximum oxygen consumption and the ADAPT quality-of-life scale. Arch Phys Med Rehabil 1982; 63:620-2.

9. Drewnowski A, Monsen E, Birkett D et al. Health Screening and Health Promotion Programs for the Elderly. Managed Health Outcomes. 2003; 11 (5): 299-309.

10. Everly, G.S. - A Clinical Guide to the Treatment of the Human Stress Response. Plenum Press, New York, 1990. 
11. Fix AJ, Daughton DM. Human activity profile - professional manual. Nebraska: Psychological AssessmentResources; 1988.

12. Folkman, S., \& Lazarus, R. S.. An analysis of coping in a middle-aged community sample. Journal of Health and Social Behavior, 21, 219-239, 1980.

13. Freire, Sueli Aparecida. Envelhecimento Bem-Sucedido e Bem-Estar Psicológico. In: Neri, Anita Liberalesso; Freire, Sueli Aparecida. (Org.). E por Falar em Boa Velhice. Campinas: Papirus, p. 21-31, 2000.

14. Freire, Sueli Aparecida; Resende, Marineia Crosara de. Sentido de Vida e Envelhecimento. In: Neri, Anita Liberalesso. (Org.). Maturidade Velhice trajetórias individuais e sócio culturais. Campinas: Papirus p.71-94, 2001.

15. Gallahue, D.L. UnderstandingMotor development: infants, children, adolescents, adults. 3.ed. Madison, WCB Brown \& Benchmarck, 1995.

16. Goldstein, Lucila L. Stress e Coping na Vida Adulta e na velhice. In: NERI, Anita Liberalesso. (Org.). Psicologia do Envelhecimento. Campinas: Papirus, p. 145-158, 1995.

17. Harris, A.H.S; Cronkiter, M.R. Physical activity, exercise coping and depression in a 10-year cohort study of depressed patients. Journal of Affective Disorders, v.93, p.79-85, 2006.

18. Hayflick, L.H. Como e por que envelhecemos. Rio de Janeiro, Campus, 1996.

19. Holmes, T. H.; Rahe, R. H. The social readjustment rating scales. Journal of Psychosomatic Research, v. 11, p. 213-218, 1967.

20. Houaiss, Antônio, Villar, Mauro de Salles, Franco, Franscisco Manoel de Mello. In: Dicionário Houaiss da Língua Portuguesa. Rio de Janeiro: Editora Objetiva Ltda, 2001.

21. Jacob Filho, W. . Prática a caminho da senecultura. São Paulo: Atheneu,2003.

22. Johnston B, Lyons WL, Covinsky KE. Geriatric Medicine. In: Tierney LM Jr.,McPhee SJ, MA Papadakis MA, editors.Curent Medical Diagnosis \& Treatment. New York:McGraw-Hill; 2004.

23. Kenney, R.A. Physiology of aging: a synopis. (2a . Ed.)Chicago/London/BocaRaton: Year Book Medical Publishers, 1989. 
24. Krause, N; Goldehar, L; Liang, J; Jay, G; Maeda, D. Stress and exercise among the Japanese elderly. Social Science \& Medicine, v.36, n.11, p.1629-1441, 1993.

25. Lawton, M. P. A Multidimensional View of Quality of Life in Frail Elders. Em: J. E. Birren, J. E. Lubben, J. C. Rowe, \& D. E. Deutchman The Concept and Measurement of Quality of Life in the Frail Elderly. (pp.3-27). San Diego: Academic Press, 1991.

26. Lazarus R, Folkman S. Stress, appraisal and coping. New York: Springer Publishing Company; 1984.

27. Lipp, M. E. N. Stress: conceitos básicos. In M. E. N. Lipp (Ed.), Pesquisas sobre o stress no Brasil: saúde, ocupações e grupos de risco (pp.17-29). Campinas: Papirus, 1996.

28. Lipp, M.E.N. (ed.) - O Stress Está Dentro de Você. Contexto, São Paulo, 2000.

29. Lipp, M. E. N., \& Malagris, L. E. N. Manejo do estresse. In B. Range (Org.), Psicoterapia comportamental e cognitiva: pesquisa, prática, aplicações e problemas (pp.279-292). Campinas: Ed. Psy II, 1995.

30. Lipp, M. E. N., \& Malagris, L. N. Manejo do stress. In B. Rangé (Ed.), Psicoterapia comportamental e cognitiva: pesquisa, prática, aplicações e problemas (pp.279291) Campinas: Editorial Psy,1998.

31. Lipp, M. E. N., \& Malagris, L. E. N. O stress emocional e seu tratamento. In B. Rangé (Org). Psicoterapias cognitivo-comportamentais: um diálogo com a psiquiatria (pp.475-490). Porto Alegre: Artmed, 2001.

32. Lipp, M. E. N., \& Novaes, L. E. Mitos \& verdades: o stress. São Paulo: Contexto, 1996.

33. Lipp, M.E.N. \& Rocha, J.C. Stress, Hipertensão e Qualidade de Vida. 2a ed. Papirus, Campinas, 1996.

34. Luft, C.B. Aspectos neuropsicológicos do envelhecimento e prática de atividade física: possíveis relações em mulheres idosas. Dissertação de mestrado, Universidade do Estado de Santa Catarina, 2007.p.45-48.

35. Mazo GZ, Lopes MA, Benedetti TB. Atividade física e o idoso: concepção gerontológica. São Paulo: Sulina; 2001. p. 13-5. 
36. McAuley, E.; \& Rudolph, D. Phiysical activity, aging, and psychological wellbeing. Journal of Aging andPhysical Activity, 3, p. 67-96, 1995.

37. Mendes de Leon, C.F.; Seeman, T.E.; Baker, D.I.; Richardson, E.D.; Tinetti, M. Self-efficacy, physical decline, and change in functioning in community-living elders: a prospective study. Journal of Gerontology: Social Sciences, v.51B, n.4, p.183-90, 1996.

38. Nahas, M. V. A atividade física, saúde e qualidade de vida: conceitos e sugestões para um estilo de vida ativo. 2. ed. Londrina: Midiograf, 2001.

39. Neri, Anita Liberalesso. Velhice e Qualidade de Vida na Mulher. In: Desenvolvimento e Envelhecimento. Campinas: Papirus, p.161-196, 2001.

40. Nieman, D. C. The exercise health connection. Champaingn, IL: Human Kinetics, 1998.

41. Okuma, S.S. $O$ idoso e a atividade física: Fundamentos e pesquisa. Campinas: Papirus, 1998.

42. Okuma, S.S. O significado da atividade física para o idoso: um estudo fenomenológico. São Paulo, 1997. 380p. Tese (Doutorado) - Instituto de Psicologia, Universidade de São Paulo.

43. Okuma, S.S.; Andreotti, R.A.; Lara, A.R.F.; Miranda, M.L.; Suckow, L. Implantação do programa de atividade física para autonomia para pessoas idosas. São Paulo, Departamento de Pedagogia do Movimento do Corpo Humano/EEFEUSP, 1995.

44. Olds, Sally W.; Papalia, Diane E. Desenvolvimento Humano. 7. ed.Porto Alegre: Artes Médicas Sul, 2000.

45. Organização Mundial da Saúde. Classificação internacional de funcionalidade, incapacidade e saúde. São Paulo: Edusp; 2003.

46. Paschoal, S.M.P. , Qualidade de vida do idoso: construção de um instrumento da avaliação através do método do impacto clínico. Tese (Doutorado). Faculdade de Medicina da Universidade de São Paulo,p.28, São Paulo,2004.

47. Passarelli, Maria Cristina G. O processo de envelhecimento em uma perspectiva geriatrica / The Ageing Process in a Geriatric Perspective; 21(4): 208-12 jul.-ago. 1997. 
48. Pate, R.R. Recent statements and initiatives on physical activity and health. Quest, Champaign, v.47, n.3, p.304-310, 1995.

49. Pereira A, Freitas C, Mendonça C, Marçal F, Souza J, Noronha JP, et al. Envelhecimento, estresse e sociedade: uma visão psiconeuroendocrinológica. Ciências \& Cognição, 2004; 1:34-53.

50. Pescatello, L. S. \& Di Pietro, L. Physical activity adults: An overview of health benefits. SportMedicine, 15, (16), p. 353-364, 1993.

51. Roizen, Michel F. Idade verdadeira: viva mais pareça menos. Rio de Janeiro: Campus, 1999.

52. Ryan-Wenger, N.M.. A taxonomy of children's coping strategies:A step toward theory development. American Journal of Orthopsychiatry, ,1992,62, 256-263.

53. Savóia M. G.; Santana 1996 P. R.; Mejias N. P. Adaptação do inventário de estratégias de coping de Folkman e Lazarus para o português. Psicologia USP, v. 7 (1/2), p. 183-201, 1996.

54. Schoueri Junior, R.; Ramos, L. R.; Papaléo Netto, M. Crescimento populacional: aspectos demogáficos e sociais. In: Carvalho Filho, E. T.; Papaléo, M. N., eds.Geriatria:fundamentos, clínica, terapêutica. São Paulo, Atheneu, 1994. p. 9- 29.

55. Selye, H. . The stress of life. Nova York: McGraw-Hill, 1956.

56. Seeman, T.E.; Bruce, M.L.; McAvay, G.J. Social network characteristics and onset ADL disability: McArthur studies of successful aging. Journal of Gerontology, v.51B, S191-200, 1996.

57. Seidl, E.M.F.; Tróccoli, B.T. \& Zannon, C.M.L.C. Análise fatorial de uma medida de estratégia de enfrentamento. Psicologia Teoria e Pesquisa, 17, 225-234, 2001.

58. Sharkey, B. J. Fitness and health. 5. ed. Cham-paign, IL: Human Kinetics, 2001.

59. Spirduso, W. W. Physical activity and aging:introduction. In: Spirduso, W.; Eckert, H., eds. Physical activity and aging. Champaign, Human Kinetics, 1989. p. 1- 5. Physical dimensions of aging. Champaign,Human Kinetics, 1995.

60. Spirduso, W.W. Dimensões Físicas do Envelhecimento. Tradução: Paula Bernardi. Barueri: Manole, 2005. 
61. Suls, J., David, J.P., \& Harvey, J.H. Personality and Coping:Three Generations of Research. Journal of Personality, 1996, p. 64, 711-735.

62. Tapp, J. T. Multisystems holistic model of health, stress and coping. Em: Stress and coping. Field, T. M., McCabe, P. M., \&Scheneiderman (Eds.). Hillsdale: Lawrence Erlbaum Associates, 1985.

63. Toates, F. - Stress: Conceptural and Biological Aspects. John Wiley \& Sons, New York, 1999.

64. THE WHOQOL GROUP. The World Health Organization Quality of Life Assessment (WHOQOL): Position paper from the World Health Organization. Social Science \& Medicine, 1998, p.41(10), 1403-1409.

65. Vaillant, G.E. Ego mechanisms of defense and personality psychopathology. Journal of Abnormal Psychology, 1994, p.103, 44-50.

66. Vitta, A.; Atividade física e bem-estar na velhice. In: NERI, A.; FREIRE, S. A. A. (Orgs.). E por falar em boa velhice. Campinas: Papirus, 2000. p. 81-90.

67. Yusuf, H. R. et al. Leisure-time physical acti-vity among older adults. Archivo Internacional de Medicina, v. 156, p. 1321-1326, 1996.

68. Zakir, Norma Sant'Ana. Enfrentamento e Percepção de Controlabilidade Pessoal e Situacional nas Reações de Stress. 2001. Tese (Doutorado em Psicologia) Pontifícia Universidade Católica de Campinas, Campinas, 2001. 


\section{Anexo 1}

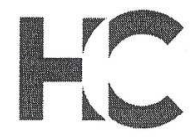

\section{APROVAÇĀO}

A Comissão de Ética para Análise de Projetos de Pesquisa CAPPesq da Diretoria Clínica do Hospital das Clínicas e da Faculdade de Medicina da Universidade de São Paulo, em sessão de 04/02/2009, APROVOU o Protocolo de pesquisa n 0655/08, intitulado: "'A A ATIVIDADE FísICA COMO ESTRATÉGIA DE ENFRENTAMENTO (COPING) DO ESTRESSE EM INDIVÍDUOS IDOSOS"." apresentado pelo Departamento de CLINNCIA MÉDICA, inclusive o Termo de Consentimento Livre e Esclarecido.

Cabe ao pesquisador elaborar e apresentar à CAPPesq, os relatórios parciais e final sobre a pesquisa (Resolução do Conselho Nacional de Saúde n 196, de 10/10/1996, inciso (X.2, letra "c").

Pesquisador (a) Responsável: Prof. Dr. Wilson Jacob Filho

Pesquisador (a) Executante: Fernando de Andréa

CAPPesq, 05 de Fevereiro de 2009

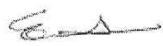

Prol. Dr. Eduardo Massad Presidente da Comissāo de Ética para Análise de Projełos de Pesquisa

Comissão de Ética para Análise de Projetos de Pesquisa do HCFMUSP e da FMUSP Diretoria Clínica do Hospital das Clinicas da Faculdade de Medicina da Universidade de São Paulo Rua Ovídio Pires de Campos, 225, $5^{\circ}$ andar - CEP 05403010 - São Paulo - SP Fone: 01130696442 Fax: 01130696492 e-mail: cappesq@ncnet.usp.br / secretariacappesq2@hcnet.usp.br 
Anexo 2

HOSPITAL DAS CLÍNICAS DA FACULDADE DE MEDICINA DA UNIVERSIDADE DE SÃO PAULO-HCFMUSP

TERMO DE CONSENTIMENTO LIVRE E ESCLARECIDO

DADOS DE IDENTIFICAÇÃO DO SUJEITO DA PESQUISA OU RESPONSÁVEL LEGAL

1. NOME: .

DOCUMENTO DE IDENTIDADE № :

SEXO :.$M \square F$

DATA NASCIMENTO:

№

……............... APTO:

ENDEREÇO

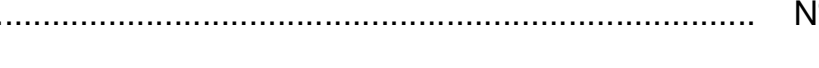

BAIRRO:

CIDADE

CEP:

TELEFONE:

DDD

$(\ldots \ldots \ldots \ldots)$

2.RESPONSÁVEL

LEGAL

NATUREZA

(grau

de

parentesco,

tutor,

curador

etc.) 
DOCUMENTO DE IDENTIDADE :

SEXO: $M \square F \square$

DATA NASCIMENTO.: .....................

ENDEREÇO:

№

APTO:

BAIRRO:

CIDADE:

CEP:

TELEFONE:

DDD

$($....................

DADOS SOBRE A PESQUISA

1. TÍTULO DO PROTOCOLO DE PESQUISA A ATIVIDADE FÍSICA COMO ESTRATÉGIA DE ENFRENTAMENTO DO ESTRESSE EM IDOSOS.

PESQUISADOR

FERNANDO

$\mathrm{DE}$

ANDRÉA

CARGO/FUNÇÃO:

PROFESSOR.

INSCRIÇÃO CONSELHO

REGIONAL № $.013825-\mathrm{G} / \mathrm{SP}$

UNIDADE

DO

HCFMUSP:

GERIATRIA

3. AVALIAÇÃO DO RISCO DA PESQUISA:

RISCO MÍNIMO

RISCO MÉDIO 
MESES.

O Senhor (a) está sendo convidado a participar de uma pesquisa cujo objetivo é avaliar a possibilidade de enfrentar o estresse através da atividade física.

Para participar dessa pesquisa, o Senhor (a) deverá responder a dois questionários. O tempo gasto pra responder esses questionários é em média de trinta minutos, quinze minutos cada.

Também para sua participação na pesquisa serão realizadas sessões de atividade física. As atividades físicas serão feitas três vezes por semana, as aulas serão na AAOC da Faculdade de Medicina USP. Estas aulas terão a duração máxima de 45 minutos, com exercícios de alongamento, fortalecimento (com elástico, bolas, corda e etc.), caminhada e relaxamento.

As atividades físicas podem causar no início,

-desconforto,

-cansaço físico, principalmente muscular,

- porém com o decorrer do programa isto será revertido com uma melhora no seu condicionamento físico.

Os riscos da pesquisa são baixos por se tratar de atividade física, composta de exercícios simples, que não precisam conhecimento anterior, nem grande condicionamento físico, de baixo impacto ministrada por um profissional de Educação Física registrado no CREF (Conselho regional de Educação física). 
Em qualquer etapa do estudo, o sr (a) terá acesso aos profissionais responsáveis pela pesquisa para esclarecimento de eventuais dúvidas. Os principais investigadores são o Dr. Wilson Jacob Filho e o Profissional de Educação Física Fernando de Andréa, que podem ser encontrados nos endereços: R Dr. Enéas de Carvalho Aguiar, 155, PAMB, 8 andar, Bloco 8 . Se você tiver alguma consideração ou dúvida sobre a ética da pesquisa, entre em contato com o Comitê de Ética em Pesquisa (CEP) - Rua Ovídio Pires de Campos, 225 - $5^{\circ}$ andar - tel.: 3069-6442 ramais 16, 17, 18 ou 20, FAX: 3069-6442 ramal 26 - E-mail: cappesq@hcnet.usp.br

Todos os dados da pesquisa (provenientes dos questionários) serão analisados em conjunto, não sendo divulgada a identificação de nenhum paciente;

O Senhor (a) poderá ser informado a respeito de todos os resultados da pesquisa se assim quiser. O Senhor (a) não terá despesas pessoais em qualquer fase do estudo, incluindo exames e consultas. Também não há compensação financeira relacionada à sua participação.

Os pesquisadores deste estudo se comprometem a utilizar os dados e o material coletado somente para esta pesquisa. Caso os resultados da pesquisa sejam publicados, os participantes não serão identificados.

Acredito ter sido suficientemente informado a respeito das informações que li ou que foram lidas para mim, descrevendo o estudo "A Atividade Física como estratégia de enfrentamento (coping) do estresse" Eu discuti com Fernando de Andréa sobre a minha decisão em participar nesse estudo. Ficaram claros para mim quais são os propósitos do estudo, os procedimentos a serem realizados, seus desconfortos e riscos, as garantias de confidencialidade e de esclarecimentos permanentes. Ficou claro também que minha participação é isenta de despesas e que tenho garantia do acesso a tratamento hospitalar quando necessário. Concordo voluntariamente em participar deste estudo e poderei retirar o meu consentimento a qualquer momento, antes ou durante o mesmo, sem penalidades ou prejuízo ou perda de qualquer benefício que eu possa ter adquirido. 
Assinatura do paciente/representante legal

Data I I

Assinatura da testemunha

Data L 1

para casos de pacientes menores de 18 anos, analfabetos, semi-analfabetos ou portadores de deficiência auditiva ou visual.

\section{(Somente para o responsável do projeto)}

Declaro que obtive de forma apropriada e voluntária o Consentimento Livre e Esclarecido deste paciente ou representante legal para a participação neste estudo.

Assinatura do responsável pelo estudo Data ! I 


\section{Anexo 3}

Perfil de Atividade Humana

\section{ATIVIDADES}

1. Levantar e sentar em cadeiras ou cama (sem ajuda)

2. Ouvir rádio

3. Ler livros, revistas ou jornais

4. Escrever cartas ou bilhetes

5. Trabalhar numa mesa ou escrivaninha

6. Ficar de pé por mais que um minuto

7. Ficar de pé por mais que cinco minutos

8. Vestir e tirar a roupa sem ajuda

9. Tirar roupas de gavetas ou armários

10. Entrar e sair do carro sem ajuda

11. Jantar num restaurante

12. Jogar baralho ou qualquer jogo de mesa

13. Tomar banho de banheira sem ajuda

14. Calçar sapatos e meias sem parar para descansar

15. Ir ao cinema, teatro ou a eventos religiosos ou esportivos

16. Caminhar 27 metros (um minuto)

17. Caminhar 27 metros sem parar (um minuto)

18. Vestir e tirar a roupa sem parar para descansar

19. Utilizar transporte público ou dirigir por 1 hora e meia

(158 quilômetros ou menos)

20. Utilizar transporte público ou dirigir por \pm 2 horas

\section{Ainda Parei de Nunca \\ faço fazer fiz}


(160 quilômetros ou mais)

21. Cozinhar suas próprias refeições

22. Lavar ou secar vasilhas

23. Guardar mantimentos em armários

24. Passar ou dobrar roupas

25. Tirar poeira, lustrar móveis ou polir o carro

26. Tomar banho de chuveiro

27. Subir seis degraus

28. Subir seis degraus sem parar

29. Subir nove degraus

30. Subir 12 degraus

31. Caminhar metade de um quarteirão no plano

32. Caminhar metade de um quarteirão no plano sem parar

33. Arrumar a cama (sem trocar os lençóis)

34. Limpar janelas

35. Ajoelhar ou agachar para fazer trabalhos leves

36. Carregar uma sacola leve de mantimentos

37. Subir nove degraus sem parar

38. Subir 12 degraus sem parar

39. Caminhar metade de um quarteirão numa ladeira

40. Caminhar metade de um quarteirão numa ladeira, sem parar

41. Fazer compras sozinho

42. Lavar roupas sem ajuda (pode ser com máquina)

44. Caminhar 2 quarteirões no plano

45. Caminhar um quarteirão no plano, sem parar

46. Caminhar dois quarteirões no plano, sem parar

47. Esfregar o chão, paredes ou lavar carros

48. Arrumar a cama trocando os lençóis

49. Varrer o chão

50. Varrer o chão por cinco minutos, sem parar

51. Carregar uma mala pesada ou jogar uma partida de boliche

52. Aspirar o pó de carpetes 
53. Aspirar o pó de carpetes por cinco minutos, sem parar

54. Pintar o interior ou o exterior da casa

55. Caminhar seis quarteirões no plano

56. Caminhar seis quarteirões no plano, sem parar

57. Colocar o lixo para fora

58. Carregar uma sacola pesada de mantimentos

59. Subir 24 degraus

60. Subir 36 degraus

61. Subir 24 degraus, sem parar

62. Subir 36 degraus, sem parar

63. Caminhar 1,6 quilômetro ( \pm 20 minutos)

64. Caminhar 1,6 quilômetro ( \pm 20 minutos), sem parar

65. Correr 100 metros ou jogar peteca, "voley“, "baseball'

66. Dançar socialmente

67. Fazer exercícios calistênicos ou dança aeróbia por cinco

minutos, sem parar

68. Cortar grama com cortadeira elétrica

69. Caminhar 3,2 quilômetros ( \pm 40 minutos)

70. Caminhar 3,2 quilômetros sem parar ( \pm 40 minutos)

71. Subir 50 degraus (2 andares e meio)

72. Usar ou cavar com a pá

73. Usar ou cavar com pá por 5 minutos, sem parar

74. Subir 50 degraus (2 andares e meio), sem parar

75. Caminhar 4,8 quilômetros ( \pm 1 hora) ou jogar 18

buracos de golfe

76. Caminhar 4,8 quilômetros ( \pm 1 hora), sem parar

77. Nadar 25 metros

78. Nadar 25 metros, sem parar

79. Pedalar 1,6 quilômetro de bicicleta (2 quarteirões)

80. Pedalar 3,2 quilômetros de bicicleta (4 quarteirões)

81. Pedalar 1,6 quilômetro, sem parar

82. Pedalar 3,2 quilômetros, sem parar

83. Correr 400 metros (meio quarteirão)

84. Correr 800 metros (um quarteirão)

85. Jogar tênis/frescobol ou peteca

86. Jogar uma partida de basquete ou de futebol 
87. Correr 400 metros, sem parar

88. Correr 800 metros, sem parar

89. Correr 1,6 quilômetro (2 quarteirões)

90. Correr 3,2 quilômetros (4 quarteirões)

91. Correr 4,8 quilômetros (6 quarteirões)

92. Correr 1,6 quilômetro em 12 minutos ou menos

93. Correr 3,2 quilômetros em 20 minutos ou menos

94. Correr 4,8 quilômetros em 30 minutos ou menos 


\section{Anexo 4}

Inventário de estratégias de coping de Folkman e Lazarus

Leia cada item abaixo e indique, fazendo um círculo na categoria apropriada o que você fez na situação

0 não usei essa estratégia

1 usei um pouco

2 usei bastante

3 usei em grande quantidade

1. Concentrei-me no que deveria ser feito em seguida, no próximo passo

2. Tentei analisar o problema para entendê-lo melhor

0123

3. Procurei trabalhar ou fazer alguma atividade para me distrair

0123

4. Deixei o tempo passar _ a melhor coisa que poderia fazer era esperar _ o tempo é o melhor remédio

0123

5. Procurei tirar alguma vantagem da situação

0123 
6. Fiz alguma coisa que acreditava não daria resultados, mas ao menos estava fazendo alguma coisa

0123

7. Tentei encontrar a pessoa responsável para mudar suas idéias

8. Conversei com outra(s) pessoa (s) sobre o problema, procurando mais dados sobre a situação

0123

9. Critiquei-me, repreendi-me.

0123

10. Tentei não fazer nada que fosse irreversível, procurando deixar outras opções.

11. Esperei que um milagre acontecesse

12. Concordei com o fato, aceitei o meu destino 0123

13. Fiz como se nada tivesse acontecido

14. Procurei guardar para mim mesmo (a) os meus sentimentos

15. Procurei encontrar o lado bom da situação

16. Dormi mais que o normal

17. Mostrei a raiva para as pessoas que causaram o problema

0123

18. Aceitei a simpatia e a compreensão das pessoas

19. Disse coisas a mim mesmo (a) que me ajudassem a sentir

20. Inspirou-me a fazer algo criativo

0123

21. Procurei a situação desagradável

0123 
32. Tentei descansar, tirar férias a fim de esquecer o problema

33. Procurei me sentir melhor, comendo, fumando, utilizando drogas ou medicação 
39. Modifiquei aspectos da situação para que tudo desse certo no final

40. Procurei fugir das pessoas em geral

41. Não deixei me impressionar, recusava-me a pensar muito sobre essa situação 0123

42. Procurei um amigo ou parente para pedir conselhos

43. Não deixei que os outros soubessem da verdadeira situação

44. Minimizei a situação recusando-me a me preocupar seriamente com ela

45. Falei com alguém sobre como estava me sentindo

46. Recusei recuar e batalhei pelo que eu queria

0123

47. Descontei minha raiva em outra(s) pessoa (s)

48. Busquei nas experiências passadas uma situação similar

49. Eu sabia o que deveria ser feito, portanto dobrei meus esforços para fazer o que fosse necessário

0123

50. Recusei a acreditar que aquilo estava acontecendo

51. Prometi a mim mesmo que as coisas serão diferentes da próxima vez

52. Encontrei algumas soluções diferentes para o problema

53. Aceitei, nada poderia ser feito

54. Procurei não deixar que meus sentimentos interferissem muito nas outras coisas que eu estava fazendo

0123

55. Gostaria de poder mudar o que tinha acontecido ou como me senti

0123 
57. Sonhava acordado (a) ou imaginava um lugar ou tempo melhores do que aqueles em que eu estava

58. Desejei que a situação acabasse ou que de alguma forma desaparecesse

59. Tinha fantasias de como as coisas iriam acontecer, como se encaminhariam 0123

60. Rezei

0123

61. Preparei-me para o pior

0123

62. Analisei mentalmente o que fazer e o que dizer

63. Pensei em uma pessoa que admiro e a tomei como modelo

64. Procurei ver as coisas sob o ponto de vista da outra pessoa

65. Eu disse a mim mesmo (a) que as coisas poderiam ter sido piores

0123

66. Corri ou fiz exercícios

0123 